Corrigendum

\title{
Corrigendum to "A Novel Aerodynamic Noise Reduction Method Based on Improving Spanwise Blade Shape for Electric Propeller Aircraft"
}

\author{
Yuhang Wu $\mathbb{D},{ }^{1}$ Yan-ting Ai, ${ }^{2}$ Wang Ze, ${ }^{3}$ Tian Jing, ${ }^{2}$ Xiang Song, ${ }^{4}$ and Yingtao Chen $\mathbb{D}^{2}$ \\ ${ }^{1}$ School of Aerospace Engineering, Shenyang Aerospace University, Shenyang 110136, China \\ ${ }^{2}$ Liaoning Key Laboratory of Advanced Measurement and Test Technology for Aviation Propulsion System, \\ Shenyang Aerospace University, Shenyang 110136, China \\ ${ }^{3}$ Geely Automobile Holdings Ltd., Hangzhou 310000, China \\ ${ }^{4}$ Liaoning Key Laboratory of General Aviation, Shenyang 110136, China \\ Correspondence should be addressed to Yingtao Chen; chenyingtao75@163.com
}

Received 21 April 2020; Accepted 28 May 2020; Published 15 July 2020

Copyright (C) 2020 Yuhang Wu et al. This is an open access article distributed under the Creative Commons Attribution License, which permits unrestricted use, distribution, and reproduction in any medium, provided the original work is properly cited.

In the article titled "A Novel Aerodynamic Noise Reduction Method Based on Improving Spanwise Blade Shape for Electric Propeller Aircraft" [1], Dr. Yuhang Wu was incorrectly listed as the corresponding author. The corresponding author is Dr. Yingtao Chen.

\section{References}

[1] Y. Wu, Y. Ai, W. Ze, T. Jing, X. Song, and Y. Chen, "A Novel Aerodynamic Noise Reduction Method Based on Improving Spanwise Blade Shape for Electric Propeller Aircraft," International Journal of Aerospace Engineering, vol. 2019, Article ID 3750451, 10 pages, 2019. 